\title{
Sujeito, espaço e lixo, no dizer da mundialização ${ }^{1}$
}

\author{
Subject, space and trash: in the saying of globalization
}

\author{
Ana Luiza Artiaga R. da Motta ${ }^{2}$ \\ Universidade do Estado de Mato Grosso
}

\begin{abstract}
- RESUMO: Este trabalho tem como proposição uma reflexão teórica e analítica sobre o discurso produzido pela Organização das Nações Unidas, em 2018, em referência ao dia mundial do ambiente. O discurso produzido em vídeo, em circulação na internet, refere-se à poluição plástica, e seus efeitos de ordem planetária. Na textualidade do vídeo, a linguagem verbal e de imagem, interpela gestos de leitura, sobre o modo como o lixo, produto plástico, toma rios e mares, vias sem fronteiras. Isto converge sentidos entre as nações, à relação do sujeito com o consumo e o espaço.
\end{abstract}

- PALAVRAS-CHAVE: ONU; Discurso; Sujeito; Lixo; Mundialização

- ABSTRACT: this paper proposes a theoretical and analytical reflection on the discourse produced by the United Nations in 2018, in reference to the World Environment Day. Video discourse circulated on the Internet refers to plastic pollution and its planetary effects. In the textuality of video, verbal and image language challenges reading gestures about the way garbage, plastic products, rivers and seas, roads without borders. This converges meanings between nations, the subject's relationship with consumption and space.

- KEYWORDS: UN; Speech; Subject; Trash; Globalization

\section{ONU modos de significação}

O objetivo deste trabalho é desenvolver, pela inscrição teórica a Análise de Discurso francesa, uma reflexão voltada ao estudo do discurso ambiental, em específico, sobre a questão do lixo plástico. Trata-se do discurso, produzido pela Organização das Nações Unidas em 2018, em vídeo, disponibilizado no YouTube.

Pelo aporte teórico deteremos ao estudo da linguagem verbal e de imagem que constitui a materialidade simbólica do vídeo de curta metragem. De modo que, a língua, a forma material, base dos processos discursivos, torna-se o lugar de estudos do sentido pelo

\footnotetext{
${ }^{1}$ Este texto parte de estudos do Projeto de Pesquisa de Pós Doutorado, no Programa de Pós-graduação em Estudos Linguísticos/POSLIN, da Universidade Federal de Minas Gerais - UFMG, sob a Supervisão do Prof. Dr. Luíz Francisco Dias.

${ }^{2}$ Doutora em Linguística. Professora do Curso de Letras e do Programa de Pós-graduação em Linguística da UNEMAT. E-mail: analuizart@terra.com.br
}

Traços de Linguagem, Cáceres, v. 3, n. 1 p. 109-124, 2019 
funcionamento da linguagem. Nessa dimensão, cabe-nos compreendermos um pouco sobre a significação da Organização das Nações Unidas - ONU.

A Organização das Nações Unidas instituída após a segunda guerra mundial se marca pelo documento denominado Carta das Nações Unidas assinado em São Francisco, a 26 de Junho de 1945, após o encerramento da Conferência das Nações Unidas sobre Organização Internacional. A carta reverbera sentidos sobre o mundo e evoca a paz e a segurança para a humanidade em confronto aos efeitos ideológicos dos flagelos de pós-guerra. O texto - Carta das Nações Unidas - é promulgado em 24 de outubro de 1945, em reunião em São Francisco, nos Estados Unidos, com representantes de 50 países, dentre estes o Brasil.

A organização internacional das Nações Unidas conta, atualmente, com 193 países, membros participantes do acordo e da Assembleia Geral das Nações Unidas. Deve-se explicitar que os cinco países: China, França, Rússia, Grã-Bretanha e os Estados Unidos participaram como membros originários das Nações Unidas, na Conferência das Nações Unidas sobre a Organização Internacional. Nessa Conferência realizada em $1^{\circ}$ de janeiro de 1942, em São Francisco, assina-se, a Declaração das Nações Unidas. De modo que os cinco países (citados) atuam de forma distintiva, como membros permanentes do Conselho de Segurança, com direito representativo de veto nas assembleias. ${ }^{3}$

O Conselho de Segurança da ONU tem a cada dois anos a escolha de outros cinco países, a fazer parte como membros não permanentes, para o mandato de dois $\operatorname{anos}^{4}$. $\mathrm{O}$ sistema, o modo de organização sobre o comum nos faz remeter ao que diz Rancière (2005, p.15) sobre a existência de um comum, mas que ao mesmo tempo tem-se nesse comum "recortes que definem lugares e partes respectivas". O que se indaga é o lugar do político na língua, nas relações de linguagem, nas intermediações do espaço, o comum, que se partilha.

Uma partilha do sensível fixa portanto, ao mesmo tempo, um comum partilhado e partes exclusivas. Essa repartição das partes e dos lugares se funda numa partilha de espaços, tempos e tipos de atividade que determina propriamente a maneira como um comum se presta à participação e como uns e outros tomam parte nessa partilha. (idem, p.15).

Conforme a Carta das Nações Unidas, os países, partícipes da Organização das Nações Unidas, têm em comum a paz e a segurança nacionais. Prevê a não intervenção em assuntos

\footnotetext{
${ }^{3}$ Disponível:https://nacoesunidas.org/carta/ acesso em outubro/2018.

${ }^{4}$ Disponível: https://pt.euronews.com/2018/06/08/cinco-novos-paises-no-conselho-de-seguranca-da-onu acesso novembro/2018.
} 
internos, as particularidades, de cada país. ${ }^{5}$ A Carta das Nações Unidas, em nota introdutória pontua:

NÓS, OS POVOS DAS NAÇÕES UNIDAS, DECIDIDOS:

A preservar as gerações vindouras do flagelo da guerra que por duas vezes, no espaço de uma vida humana, trouxe sofrimentos indizíveis à humanidade; A reafirmar a nossa fé nos direitos fundamentais do homem, na dignidade e no valor da pessoa humana, na igualdade de direitos dos homens e das mulheres, assim como das nações, grandes e pequenas;

A estabelecer as condições necessárias à manutenção da justiça e do respeito das obrigações decorrentes de tratados e de outras fontes do direito internacional;

A promover o progresso social e melhores condições de vida dentro de um conceito mais amplo de liberdade.

No texto da Carta das Nações Unidas, em nota introdutória, observa-se ao fio do discurso o modo como a ONU, na posição de organização institucional, se inscreve - "Nós os povos das nações unidas decididos a: A preservar as gerações vindouras do flagelo da guerra [...]/ A reafirmar a nossa fé nos direitos fundamentais do homem [...]/ a estabelecer as condições necessárias à manutenção da justiça [...]/ A promover o progresso social e melhores condições de vida [...]." $\mathrm{Na}$ formulação "nós", os "povos" [...] observa-se um jogo pela linguagem pelas estruturas enunciativas que converge a uma abstração de sentido plural e de coletividade o que não é uno. O pronome pessoal de tratamento nós $-1^{\mathrm{a}}$ pessoa do plural - ao fio do discurso, produz um indicativo de quem seja o nós - os povos. Estes, povos, de distintas nações, filiados à Organização tomam corporeidade no discurso. A questão que suscita compreensão é: como o sentido se constitui pelo discurso?

Com M. Pêcheux (1995, p.160), em Semântica e Discurso, compreende-se que a ideologia trabalha, na materialidade da língua, e, é quem fornece "as evidências que fazem com que uma palavra ou enunciado "queiram dizer o que realmente dizem" e que mascaram, assim, sob a "transparência da linguagem", aquilo que chamaremos o caráter material do sentido das palavras e dos enunciados." Isto significa que o sentido de uma palavra não consiste em sua literalidade, mas é constituído, determinado pelas posições ideológicas.

O discurso condensa na materialidade da língua, o efeito ideológico, em que o sentido não subsiste por si próprio. De modo que para que as palavras proferidas se signifiquem sustentadas por aqueles que as dizem tem, necessariamente, a ver com as

\footnotetext{
${ }^{5}$ Disponível: https://super.abril.com.br/mundo-estranho/como-foi-criada-a-organizacao-das-nacoes-unidas/ acesso novembro/2018.
}

Traços de Linguagem, Cáceres, v. 3, n. 1 p. 109-124, 2019. 
formações discursivas, que constituem as formações ideológicas. Nesse sentido, o dizer da ONU congrega um espaço de um dizer institucional, atravessado por distintas posições políticas e ideológicas. Assim, para que o discurso faça sentido, torna-se necessário compreender o modo como o sentido se constitui em cada formação discursiva (PÊCHEUX, 1995). Ou seja, o sentido não se constrói no reduto do texto, mas pelas disjunções, deslocamentos, a historicidade que movimenta as formações discursivas.

Para P. Henry (1993),

Os fatos de sentido da ordem do discurso não são remissíveis ao discurso de um sujeito, nem mesmo aos de vários conjuntos para fazer uma espécie de "sujeito médio", mas a "formações discursivas" que não têm realidade no nível do indivíduo, senão pelo fato de que elas determinam as posições que pode e deve ocupar todo indivíduo, para ser o sujeito de uma enunciação provida de sentido. (HENRY, 1993, p.162).

Segundo P. Henry (op.cit.), o sentido não está galgado no discurso do sujeito, no nível do indivíduo, nem ao conjunto "sujeito" que diz sobre determinado fato, mas nas formações discursivas. De modo que, na formulação da Carta das Nações Unidas ao evocar, em nota introdutória - "Nós, os povos das nações unidas decididos [...]" - tem-se no/pelo uso do pronome pessoal a pluralização - "nós" "os povos das nações unidas" - como representativos de um segmento organizacional. É, preciso, entretanto, fazer intervir pela formulação os sentidos transversos que constituem o sentido à formulação. Conforme P. Henry (1993) o processo de constituição do sentido não são da ordem daquele que diz o discurso. Ou seja, o sentido é constituído pelas formações discursivas. Vejamos o recorte.

Dentre os objetivos.

1.Manter a paz e a segurança internacionais e para esse fim: tomar medidas colectivas eficazes para prevenir e afastar ameaças à paz e reprimir os actos de agressão, ou outra qualquer ruptura da paz e chegar, por meios pacíficos, e em conformidade com os princípios da justiça e do direito internacional, a um ajustamento ou solução das controvérsias ou situações internacionais que possam levar a uma perturbação da paz;

2.Desenvolver relações de amizade entre as nações baseadas no respeito do princípio da igualdade de direitos e da autodeterminação dos povos, e tomar outras medidas apropriadas ao fortalecimento da paz universal;

3.Realizar a cooperação internacional, resolvendo os problemas internacionais de carácter económico, social, cultural ou humanitário, promovendo e estimulando o respeito pelos direitos do homem e pelas liberdades fundamentais para todos, sem distinção de raça, sexo, língua ou religião; 
4.Ser um centro destinado a harmonizar a acção das nações para a consecução desses objectivos comuns. ${ }^{6}$ ( Carta das Nações Unidas).

No excerto, a Carta das Nações Unidas, coloca-se em proposição “[...] a cooperação internacional, resolvendo os problemas internacionais de caráter econômico, social, cultural ou humanitário [...]". Conforme referimos, em parágrafos anteriores, o sentido não está na palavra, mas na formação discursiva. Nesse sentido, entendemos o que não se diz, nesse recorte, porém se significa pelas diferentes formações discursivas, sobre o que já foi dito sobre a realização da cooperação internacional, "o respeito pelos direitos do homem e pelas liberdades fundamentais para todos, sem distinção de raça, sexo, língua ou religião". Há a ordem do discurso, todavia, “[...] deve-se distinguir entre ordem e organização, sendo a ordem do domínio do simbólico (sistematicidade sujeita a equívoco) na relação com o real, enquanto a organização refere ao empírico e ao imaginário (o arranjo das unidades)". (ORLANDI, 1999, p.08). A Análise de Discurso visa a compreensão do sentido, pois é pela ordem do simbólico que se deslineariza e trabalha-se o equívoco.

De modo que o texto da Carta das Nações Unidas torna-se instigante compreendê-lo, pelo discurso, pelo mecanismo de dizer sobre o planeta em equilíbrio, respeito pelos direitos do homem e da cooperação internacional, embora se tenha no real da história as dissimetrias e dissimilaridades econômicas e sociais a palavra chave torna-se: "Manter a paz e a segurança internacionais e para esse fim: tomar medidas colectivas eficazes para prevenir e afastar ameaças à paz e reprimir os actos de agressão, ou outra qualquer ruptura da paz”. A paz e a segurança são termos delineados em espiral, pelo discurso, de forma linear, como aquele que deva ser consenso entre os países. Em outras palavras, é uma leitura em meios a outras leituras possíveis que o texto permite depreender. Pelo gesto de interpretação, na posição de analista de discurso, entende-se que "a leitura pode ser pensada justamente como a construção dessa relação entre discurso e texto [...]”. (ORLANDI, 2001, p.70).

De modo que o texto pelas engrenagens, materialidade simbólica, oferece, pelo discurso, elementos, pistas, para leituras possíveis. Assim, o fato de se dizer da necessidade da paz e da segurança, implica, a nosso ver, compreender como o efeito do discurso global opacifica as desigualdades e dissimilaridades próprias do capitalismo, que produz a segregação.

\footnotetext{
${ }^{6}$ https://www.cm-vfxira.pt/uploads/writer file/document/14320/Carta das $\mathrm{Na}$ es Unidas.pdf acesso em novembro/2018.
}

Traços de Linguagem, Cáceres, v. 3, n. 1 p. 109-124, 2019. 
A segregação torna-se um modo de violência, de insegurança que passa pelo econômico, o financeiro e o social, qualidade de vida. O que podemos dizer que, pela nossa inscrição teórica à Análise de Discurso, o sentido não se fecha no limite da escritura do texto. O sentido escapa aos limites do texto, há brechas para outras leituras possíveis. "Há diferentes versões de um texto, que constituem tantas outras formulações; há diferentes versões de leitura que constituem tantos modos de compreensão distintos.” (op.cit. p.70). Assim, chegamos pelo gesto de interpretação, das versões de leitura, à política da significação, o modo como o discurso evoca pelas formações discursivas o sentido. Entendendo que o texto é constituído pelas discursividades entrecruzadas e que o sentido não se assenta no linear em que se grafa o texto - escrito, imagem, etc, - mas na tessitura, modo de funcionamento. E é esse modo de compreender o texto, os fios que o constitui que nos faz remetê-lo a exterioridade que o significa.

De forma que a posição instituída a ONU, regida na/pela Carta das Nações Unidas incide sobre uma política organizacional de segurança e da paz global. O espaço torna-se o comum nas relações interplanetárias, embora cada espaço/nação tenha suas diferenças. De modo que sentidos entrecruzam sobre as nações e questões escamoteiam ao termo mundialização, o lugar do político na linguagem sobre o comum - o espaço. Com que efeito?

\section{Mundialização efeitos de sentido}

A palavra Mundialização tem, no contemporâneo, um movimento de sentidos, ações planetárias. Um efeito de transbordamento. Há uma vazão de sentidos de expansão, dimensão global no termo mundialização que se dilata, transborda do poder local para o mundo e vice versa. Um movimento frenético, de velocidade tecnológica em que se produz o enredamento do sujeito, pelo discurso, pelo material significante: a ordem da língua.

De modo que a denominação mundialização incita, questões, leituras, as formações imaginárias sobre o planeta como uno. As redes tecnológicas de linguagem televisão, celular, internet, satélites funcionam como uma forma, de expansão e de "unificação" do espaço pelo imediatismo.

Brunel $(2007)^{7}$ diz que a mundialização essa criação de um espaço interdependente não é novo. Pontua que desde o Império Romano data-se uma primeira mundialização de

\footnotetext{
${ }^{7}$ Artigo Sciences Humaines/ MENSUEL nº180S, Février, 2007.
} 
forma organizada em torno do Mediterrâneo ${ }^{8}$. Salienta, porém, que essa difusão também é marcada no século XV pela conexão entre os povos, sociedades. A Terra, nessa dimensão, é compreendida como o lugar da criação, da economia mundial. Ainda segundo a autora (op.cit.) a mundialização centrada sobre o Atlântico culmina no século XIX, entre 1870 e 1914, em relação à abertura de rotas marítimas do Canal de Suez no Panamá com fins de trocas de mercadorias. Trata-se de um modo de expansão do mundo, da economia da Europa.

Ainda com Brunel (op.cit.), depreende-se que a mundialização como conhecemos, hoje, começa há um século e meio. Todavia, enfatiza que a evolução não é linear. De modo que a autora pontua acontecimentos importantes que engendram sentidos a tessitura da palavra mundialização. Em foco, a primeira guerra mundial e depois a grande depressão dos anos 1930 como pontos incisivos que provocam a ascensão dos nacionalismos estatais, uma fragmentação do mercado. Diz que a globalização nao está na agenda até a segunda guerra mundial.

Brunel (op.cit.) pontua os efeitos constitutivos da segunda guerra mundial, a guerra fria, a constituição dos blocos que congelam o mundo por quase meio século. Mas, nesse percurso sócio histórico e político, ideologicamente, a globalização, de que falamos hoje, já está tomando forma, corporeidade no mundo modernizador. Ainda segundo a autora, a abolição do espaço mundial converge, necessariamente, sob a influência de uma generalização do capitalismo com o desmantelamento das fronteiras físicas e regulatórias. Conforme Brunel (op.cit.) as questões da mundialização têm a ver com - internacionalização a exportação. A transnacionalização - fluxos de investimentos no exterior. A globalização - as redes de produção, as tecnologias de informação e comunicação.

La mondialisation actualle, ce "processus gèohistorique d' extension progressive du capitalisme à l' èchelle planétaire". Selon la formule de Laurent Carroué est à la fois une idéologie - le libéralisme - une monnaie - le dollar - un outil - le capitalisme - un système politique - la démocratie - une langue - l'anglais. ${ }^{9}$ (BRUNEL, 2007, p.28).

De modo que a globalização moderna, esse "processo geo-histórico de extensão progressiva do capitalismo em escala planetária", de acordo com a fórmula de Laurent

\footnotetext{
${ }^{8}$ (Na Europa, os países banhados pelo Mediterrâneo são Espanha, França, Mônaco, Itália, Malta, Eslovênia, Croácia, Bósnia, Hezergovina, Montenegro, Albânia, Grécia e Turquia. Na Ásia, Síria, Líbano, Israel e Palestina; e na África, Egito, Líbia, Tunísia, Argélia e Marrocos).

9 A globalização moderna, esse "processo geo-histórico de extensão progressiva do capitalismo em escala planetária". De acordo com a fórmula de Laurent Carroué, é tanto uma ideologia - o liberalismo - uma moeda - o dólar - uma ferramenta - o capitalismo - um sistema político - a democracia - uma língua - o inglês. (Tradução nossa).
}

Traços de Linguagem, Cáceres, v. 3, n. 1 p. 109-124, 2019. 
Carroué, é tanto uma ideologia - o liberalismo - uma moeda - o dólar - uma ferramenta - o capitalismo - um sistema político - a democracia - uma língua - o inglês (BRUNEL, 2007).

As leituras a partir de Brunel (op.cit.) permite uma reflexão sobre os efeitos de sentido da palavra mundialização, globalização no modo como tomam corporeidade em distintos discursos entre nações e que se significam, no modo de vida contemporâneo - na política, na economia, na língua nas percepções de tempo e espaço.

Para Ferreira (1996), ao dizer sobre os efeitos da globalização remete ao ambiente, como o comum. Traz à tona que "a qualidade ambiental é essencialmente um bem público" (p.135). De modo que o ambiente, o poder local, as ações, não estão dicotomizadas do espaço global, o ecossistema. Assim, quando a Organização das Nações Unidas/ONU coloca em circulação o vídeo produzido em 2018, faz o pedido: "Combata a poluição Plástica”. O dizer se inscreve em uma perspectiva do discurso ecológico internacional, que ressoa, ideologicamente, como ordenança para as nações. Ou seja, combata a poluição plástica.

O discurso ecológico, de preservação ambiental ${ }^{10}$, tem em sua historicidade um percurso que versa sobre o "comum", o Planeta Terra. As diferenças econômicas, políticas e sociais, de cada país marcam estruturalmente as suas condições de produção, "no jogo variável das formas que permutam o presente com o passado e o futuro". (PÊCHEUX, 1990, p.08).

De forma que tentaremos, dizer, de forma breve, sobre o percurso sócio histórico que constitui a memória discursiva do discurso ambiental. Em 1972, na Conferência de Estocolmo com representantes de Estados nacionais e internacionais dissemina-se a palavra sustentabilidade e desenvolvimento sustentável. Época em que se discute o sujeito e a sua relação com o espaço, os efeitos tecnológicos, como a chuva ácida nos Estados Unidos, entre outros fatos que significam para o mundo ${ }^{11}$. Nessa década, de 70, o Brasil encontra-se destituído de uma política ambiental, porém com a Constituição Federal de 1988, Art. 225, inaugura-se um capítulo que diz das relações do sujeito de direito com o espaço ambiental. Em 1992, no Rio de Janeiro, ocorre a Conferência das Nações Unidas sobre o Meio Ambiente e Desenvolvimento e Documentos Resultantes. O Rio+20, A escrita da Carta da Terra entre outros tratados e protocolos internacionais assinados, nos últimos anos, soma-se como parte da memória discursiva sobre a questão do ambiente ${ }^{12}$.

\footnotetext{
10 - VER - MOTTA (2003) sobre o discurso ecológico.

${ }^{11}$ Ver FERREIRA, Leila da Costa. A Questão Ambiental: sustentabilidade e políticas públicas no Brasil. 1998.

${ }^{12}$ Ver MOTTA - (2003).
} 
Dos acontecimentos políticos, ideológicos que comprimem e compartimenta o mundo a questão, a nosso ver, converge sobre a ordem do simbólico e do seu modo de funcionamento no qual se tramam as relações entre língua e história. Assim, questiona-se a materialidade da língua e a da história, o modo de funcionamento.

\footnotetext{
É bem verdade que é ilusório colocar para a história uma questão de origem e esperar dela a explicação do que existe. Ao contrário, não há "fato" ou "evento" histórico que não faça sentido, que não peça interpretação, que não reclame que lhe achemos causas e consequências. É nisso que consiste para nós a história, nesse fazer sentido, mesmo que possamos divergir sobre esse sentido em cada caso. (HENRY, 1997, p.51-52).
}

O sentido, o fazer sentido. É sobre isso, o investimento analítico, à materialidade simbólica a seguir.

\section{DAS ANÁLISES}

\section{Em questão: sujeito, espaço e lixo}

Neste trabalho, as análises consistem sobre o discurso proferido em 2018, pelo Secretário Geral da Organização das Nações Unidas, o Sr. Antônio Gutterres, em referência ao dia mundial do Ambiente. O discurso produzido em vídeo, divulgado na internet, no site do YouTube, faz pensar a posição do porta voz .

O destino do porta-voz circula assim entre a posição do profeta, a do dirigente e a do homem de Estado, visto que ele é o ponto em que "o outro mundo" se confronta com o estado de coisas existente, o ponto de partida recíproco no qual a contradição vem se amarrar politicamente a um "negocio de Estado". (PÊCHEUX, 1990, p.18).

Pelo discurso se observa a posição sujeito, as relações entre língua e história. A língua passível de jogo, de equívoco. Assim, o discurso do Secretário Geral das Nações, em narratividade oral, no vídeo, em idioma da Língua Inglesa, acompanha as cenas do texto visual e verbal, grafado em legenda em Língua Portuguesa.

Há, historicamente, uma sobredeterminação da linguagem verbal em detrimento ao não verbal. Esse agenciamento da leitura ao verbal remete a Linguística. Conforme Orlandi (1996), a teoria da Análise de Discurso pela inscrição teórica restitui, pelo discurso, modos distintos de leitura e de se discutir as diferentes materialidades.

Traços de Linguagem, Cáceres, v. 3, n. 1 p. 109-124, 2019. 
No texto em vídeo ${ }^{13}$ o Secretário Geral da ONU na posição de porta voz da Organização das Nações Unidas diz para o mundo sobre o lixo plástico e seus efeitos. $\mathrm{O}$ discurso torna-se um acontecimento histórico no dia Mundial do Ambiente, com milhões de acesso no site do YouTube. As imagens que perfilam no vídeo impõem sentidos a significação de resíduos de produtos plásticos, que a cada ano, desembocam para os oceanos, em media mais de 8 milhões de toneladas de lixo plástico.

$\mathrm{O}$ discurso reverbera sentidos sobre o tempo presente e o futuro do planeta. O visível e o invisível o alhures o irrealizado, mas que poderá vir a ser. Interessante pensar sujeito/consumo/espaço, sujeito/espaço/lixo, sujeito/discurso/ecologia.

De forma que o discurso, as cenas imagéticas, no vídeo, a materialidade simbólica abre-se a distintos questionamentos, a memória discursiva, o interdiscurso e o intradiscurso pelo efeito do discurso, do que se formula, como também do que já foi propalado sobre espaço/lixo, lixo/reciclagem e em sentido oposto espaço/lixo tal como o que se visualiza no texto em vídeo. Fragmentos de plásticos, lixo que flui e degrada as águas oceânicas. “[...] fragmentos invulneráveis ao controle [...]" (BAUMAN, 1999, p.38).

No flagrante da imagem, no fotograma, (fig.01), evoca a memória discursiva, o intradiscurso, e o interdiscurso pelo que se formula e visualiza. Lagazzi (2015) tem abordado em seus trabalhos um estudo que "diz respeito a deslinearização da imagem pela remissão do intradiscurso ao interdiscurso." (p.182). De modo que, teoricamente, a imagem tem a sua significação. Samain (2012) pontua, entre outras palavras, que a imagem não é uma bola de sinuca. Para a autora “[...] toda imagem é uma memória de memórias, um grande jardim de arquivos declaradamente vivos.” (p.23). Diremos, então, que a imagem significa, pois encadeia sentidos, memória discursiva. Conforme Souza (2001) a imagem "é sustentação de outros discursos" (p.71).

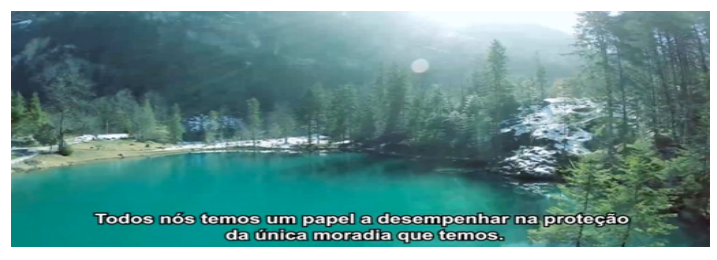

O texto, fotograma, (01), é constituído pela imagem e a formulação - "Todos nós temos um papel a desempenhar na proteção da única moradia". O quadro do texto, recorte do vídeo/ONU, se apresenta de forma naturalizado, o lugar comum o ambiente. Todavia, há

\footnotetext{
${ }^{13}$ Disponível: https://www.youtube.com/watch?v=cZNwiDrWOwU acesso em julho/2018.
} 
sentidos entrecruzados entre o texto de imagem e o verbal que encapsula o sujeito à proteção do ambiente. Não há um lugar de moradia dentro e outro fora há uma "única moradia"- o Planeta Terra. De modo que pela formulação, o pronome indefinido, interpela "todos" sem distinção e pluraliza o acontecimento pelo uso da $1^{\mathrm{a}}$ pessoa no plural, do pronome pessoal "nós". "No dizer o sujeito é flagrado, capturado pelo efeito do discurso da mundialização que institui o planeta uno, global, não dividido, mas componente da mesma biosfera". (MOTTA, 2016, p. 216). Nesse sentido, a materialidade simbólica, discursiva, capitaneia o sujeito, interpela-o a gestos de interpretação ao que se tece nos meandros do discurso ambiental. Vejamos.

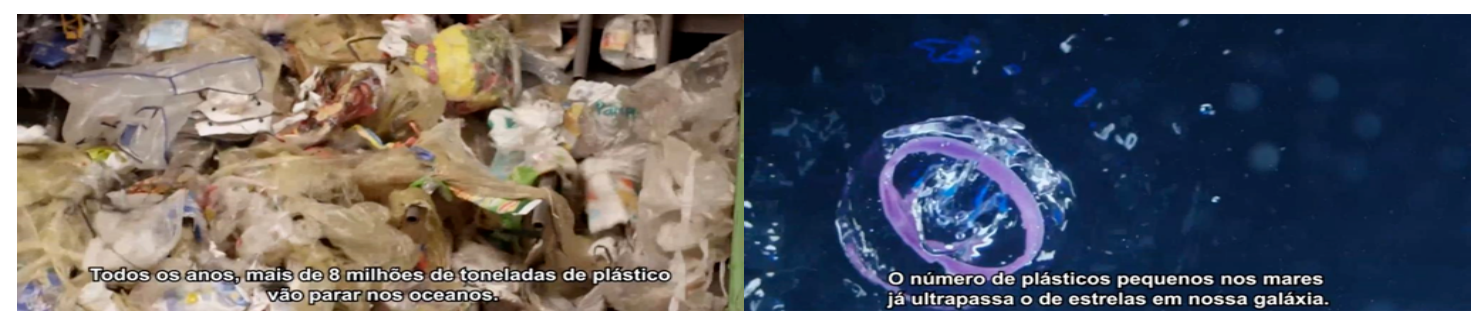

(02 e 03)

Os fotogramas, (02 e 03), recorte do vídeo da ONU/2018, apresentam uma dimensão política da significação do consumo/espaço. Espaço/lixo plástico. O texto de imagem interpela o sujeito à leitura. Há cores, luminosidade, composição visual em cena. No fotograma, imagens e escrita impõem sentidos sobre o ambiente. Significa distintamente a trajetória da memória discursiva, o interdiscurso. De modo que há sentidos em desalinho, controverso à segurança, a paz. "Todos os anos, mais de 8 milhões de toneladas de plástico vão parar nos oceanos." "O número de plásticos pequenos nos mares já ultrapassa o de estrelas em nossa galáxia.

Desse modo, no vídeo, as distintas materialidades discursivas são atravessadas por distintas formações discursivas, formações imaginárias sobre lixo, degradação, reciclagem e ambiente. De forma que, nos recortes dos fotogramas (01 a 06), a ambiência aponta para dois mundos possíveis: o preservado e o poluído. A questão que se retorna: proteção ao mundo, única moradia. Assim, "Se as tendências atuais continuarem até 2050, nossos oceanos terão mais plásticos que peixes". Pela formulação mais significa menos. Uma antítese. Portanto, diz o porta-voz da ONU: - "No dia Mundial do Ambiente, a mensagem é simples: diga não ao uso do plástico descartável." "Juntos podemos traçar um caminho para um mundo mais limpo e

Traços de Linguagem, Cáceres, v. 3, n. 1 p. 109-124, 2019. 


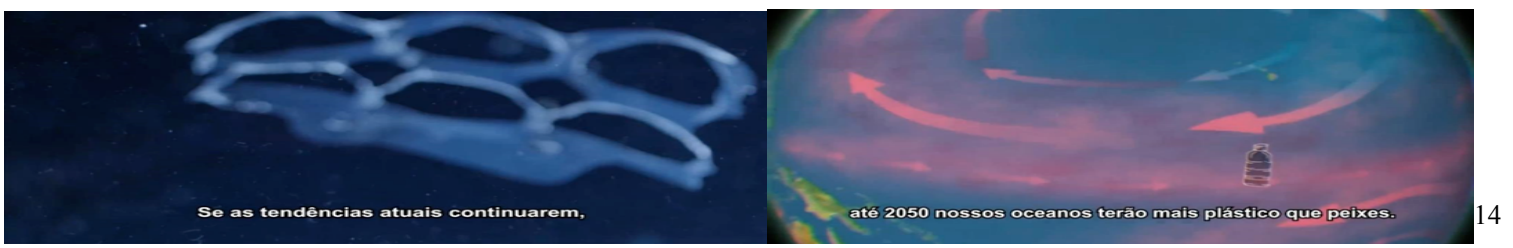

(04 e 05)

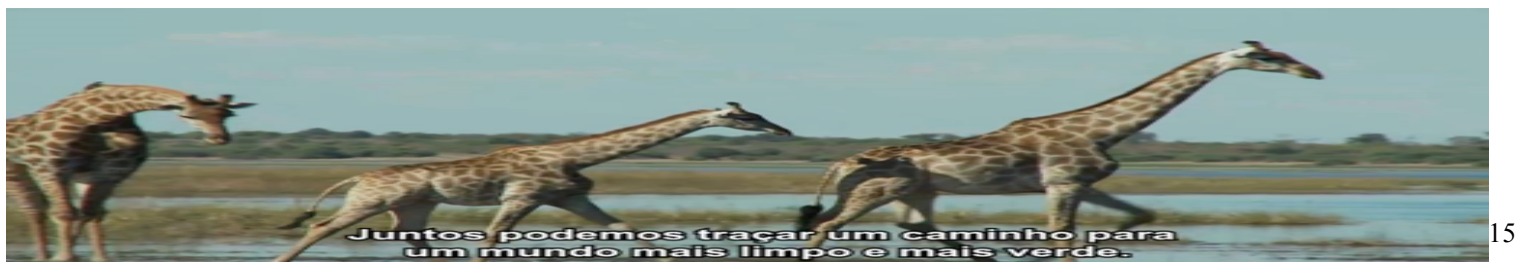

(06)

As imagens (01 a 06), fotogramadas do vídeo da ONU configuram a proposição do lugar comum, o ambiente. Há um jogo de imagens, cores, luminosidade e escrita que se expõe ao olhar do sujeito leitor. Aumont (1993), diz da importância do olho que vê "[...] que esse órgão não é um instrumento neutro que se contenta em transmitir dados tão fielmente quanto possível, mas, ao contrário, um dos postos avançados do encontro do cérebro com o mundo: partir do olho induz, automaticamente, a considerar o sujeito que utiliza esse olho para olhar uma imagem [...]" (p.77). O autor o chama de espectador.

Diferentemente, do que diz Aumont, (op.cit.) do ponto de vista teórico da Análise de Discurso, há questionamentos à materialidade discursiva. Há diferentes gestos de interpretação (Conf. ORLANDI, 1996). E, é, pela diferença, pela inscrição teórica que media o olhar, que se observam as incisões. Dias (2018), em seu trabalho sobre a significação pontua a necessidade em abrir o leque de observação, de enxergar "tanto no conhecimento da significação, quanto no conhecimento da nossa língua, pela enunciação". (p.27). Para o autor falar do olhar a linguagem, tem a sua significação - "Trata-se de um olhar teórico". (p.28). Para Lagazzi (2015) compreender a imagem significa um investimento "no procedimento de descrição dessa materialidade que mobiliza o olhar em composições equívocas.” (p.177). A autora corrobora com o que formula Pêcheux (1997) ao pontuar que "A primeira exigência consiste em dar o primado aos gestos de descrição das materialidades discursivas". (p.50).

\footnotetext{
${ }^{14}$ Recortes do vídeo - Fotograma - Jaime M. França e Rangel G. Sacramento/UNEMAT

${ }^{15}$ Fotogramas (01 a 06) - vídeo - Organização das Nações Unidas -

Vídeo - Disponível em: https:/www.youtube.com/watch?v=cZNwiDrWOwU Acesso em julho/2018.
} 
Essa descrição que o autor se refere trata-se do "reconhecimento de um real específico sobre o qual ela se instala: o real da língua" (p.50).

De modo que o trabalho com o texto verbal e de imagem requer que se desnude, deslinearize o olhar à opacidade do texto pelo gesto teórico que media a interpretação, no/pelo processo analítico. Dessa forma, o trabalho com o simbólico com a compreensão do sentido não é evidente. Nessa linhagem onde se lê na cena do vídeo - "a mensagem é simples: diga não ao uso do plástico descartável". Diremos não ser tão simples, pelo fato da demanda de interpretação, da densidade semântica da formulação. O termo "mensagem" faz pensar a linguagem como instrumento de comunicação: o emissor - a mensagem - o código - receptor. E o sentido? Como se sabe, entre o dizer e o fazer há uma diferença, que não se lineariza ao apagar das luzes.

\section{Finalizando...}

Podemos dizer que pelos diferentes gestos de interpretação, de materialidades discursivas significantes, observamos a ordem do político, do econômico, o capitalismo no discurso da globalização. O modo como o lixo plástico, produto do consumo ordinário, mundializa as relações significa no espaço. Como salienta Viola (1987), a questão ambiental não tem pátria, fronteira. Desloca-se, expande-se, e, ideologicamente, se tocam do poder local ao global e vice-versa. A ambiência abarca o capitalismo, a moeda de troca, a economia, o lixo. O movimento sócio-histórico e político das nações.

O sujeito é parte significante do planeta. O sujeito media suas relações com o mundo pela linguagem (ORLANDI, 1999). Produz leitura, se significa, constrói história. Challer (2008), do ponto de vista sociológico, compreende o sujeito, como sujeito aprendente em sociedade. Segundo o autor "[...] a pluralidade e a heterogeneidade das lógicas que orientam a "experiência social", por meio das quais se redefine um mundo comum [...]”. (SCHALLER, 2002, p.149). Esse autor pontua o sujeito as suas experiências, faz pensar o social. Pela nossa inscrição teórica entendemos, diferentemente, a questão do sujeito, enquanto posição sujeito. Isto implica compreender a relação da língua, necessariamente, com as formações sociais, pelo discurso, em que se se projeta a sua posição social e que permite, pelas análises, compreender as formações imaginárias.

Assim, o discurso da Organização das Nações Unidas faz pensar conforme Pêcheux (1997) "no ponto de encontro de uma atualidade e uma memória” (p.17). Ou seja, textualiza,

Traços de Linguagem, Cáceres, v. 3, n. 1 p. 109-124, 2019. 
recorta acontecimentos que incidem sobre a degradação do planeta. Nesse movimento de linguagem, faz pensar o modo de funcionamento da memória discursiva. Conforme Orlandi (2011) a memória discursiva “é irrepresentável" (p.55). Ela funciona pelos sentidos transversos que o habitam, movimentam. Como formula Pêcheux (1997) o "discurso não é independente das redes de memórias e dos trajetos sociais dos quais ele irrompe”. (p.56). As redes de memória que particularizam os países, o modo como cada qual se individua frente à proposição de dizer sobre a questão do lixo plástico de diferentes espécies.

O lixo tem a sua linguagem. Fragmentos do lixo, o plástico remete a industrialização, a propagandas e seus efeitos ideológicos de consumo. Pêcheux (2011) pontua que as propagandas governamentais se intensificam tanto na esfera capitalista como a do "socialismo existente". Diz sobre o termo guerra ideológica e que tem como ponto de embate discursivo "as diversas operações midiáticas de massa desenvolvidas (em média de maneira eficaz) pela grande burguesia multinacional contra tudo o que resiste a sua política". (p.73). Em continuidade o autor textualiza que "A ideia subjacente é que é preciso responder por uma contra-propaganda ainda mais eficaz: à guerra como na guerra...” (p.73). Essa formulação a partir de Pêcheux remete ao próprio engajamento político do mercado capital.

No caso da globalização, da moeda, da língua, etc., perpassa a um movimento, modo de colonização pela indústria em que a propaganda perfila a cadeia planetária do consumo. A tecnologia enquanto dispositivo de massa, de mídia, mercado capital, tem ao fio do discurso o espaço mercadológico. De certa forma, a posição discursiva da mídia, do consumo, de uma guerra permanente. Um ir e vir, ziguezagueando sentidos.

Por fim, o discurso que se produz com a globalização acende as nações as questões políticas e sociais no poder local. Entendemos que a midiatização passa pela linguagem, tal qual a relação do homem com o mundo. Nesse movimento, a língua, conforme Pêcheux (1995), para construir sentidos, para significar inscreve-se na história. Assim, sujeito, história e ideologia se imbricam, se constroem, produzem sentidos.

\section{REFERÊNCIAS}

AUMONT, Jacques. A imagem. Trad.: Estela dos Santos Abreu e Claudio C. Santos. Campinas, SP: Papirus, 1993.

BAUMAN, Zygmunt. Globalização: as consequências humanas. Trad. Marcus Penchel. RJ: Zahar, 1999.

BRUNEL, Sylvie. Quést-ce que la mondialisation?. In: 10 questions sur la mondialisation, Spécial Sciences Humaines, nº1805, Mars. Paris, 2007.

DIAS, Luiz Francisco. Enunciação e relações linguísticas. Campinas, SP: Pontes, 2018. 
FERREIRA, Leila da Costa. A Questão Ambiental: sustentabilidade e políticas públicas no Brasil. São Paulo: Editora Boitempo, 1998.

HENRY, Paul. Apêndice: Sentido, Sujeito, Origem. In Discurso Fundador: a formação do país e a construção da identidade nacional.Campinas, SP: 1993

LAGAZZI, Suzy. Paráfrases da imagem e cenas prototípicas: em torno da memória e do equívoco. In: Análise de Discurso em rede: cultura e mídia. V.1. Flores, Giovanna G. Benedetto. et al. (org.). Campinas, SP: Pontes, 2015.

MOTTA, Ana Luiza A. Rodrigues da. O sujeito no discurso ecológico sobre a pesca na cidade de Cáceres Estado de Mato Grosso. Dissertação de Mestrado - UNICAMP, Campinas, SP: 2003.

A ambiência do discurso ecológico no poder local. In: Sujeito e Memória: lugares constitutivos. NUNES, Silvia. et al. (org.). Campinas, SP: Pontes, 2016.

ORLANDI, Eni Pulcinelli. Interpretação: autoria leitura e efeitos do trabalho simbólico. Petrópolis, RJ. Vozes, 1996.

Escritos n.05. Revista do Núcleo de Desenvolvimento da Criatividade da UNICAMP - NUDECRI. Campinas, SP. Número especial, julho 1999.

No limiar da cidade. In Revista Rua: Revista do Núcleo de Desenvolvimento da

Criatividade da UNICAMP - NUDECRI. Campinas, SP. Número especial, julho 1999.

Enfoque linguístico / discursivo da educação ambiental. In: Gaia e Ecoar de

Educação Ambiental, 1996.

Análise de discurso: princípios e procedimentos. Campinas, SP. Pontes, 1999.

Discurso e Texto. Campinas, SP: Pontes, 2001

Documentário: acontecimento discursivo, memória e interpretação. In: Leituras do

político. (Org). Ana Zandwaus e Lucília Maria S. Romão. Porto Alegre: Ed. UFRGS, 2011.

PÊCHEUX, Michel. Delimitações, Inversões, Deslocamentos. In, Cadernos de Estudos Linguísticos. Campinas, SP. 1990.

Semântica e discurso: uma crítica à afirmação do óbvio. (trad.) Eni P.Orlandi. 2. ed. Campinas, UNICAMP, 1995.

Ler o Arquivo Hoje. In. Gestos de leitura: da História no Discurso. Campinas, SP. UNICAMP, 1997.

"Análise automática do discurso" (AAD-69). in: F. Gadet \& T. Hak (orgs.). Por uma análise automática do discurso; uma introdução à obra de Michel Pêcheux. Campinas, SP: UNICAMP, 1997.

Papel da Memória. In. Papel da Memória. Campinas, SP. Pontes, 1999.

Análise de Discurso: Michel Pêcheux. Textos selecionados: Eni P. Orlandi. Campinas, SP: Pontes, 2011.

RANCIÈRE, Jacques. A partilha do sensível: estética e política. Trad. Monica C. Netto. São Paulo: EXO experimental org.; Ed. 34, 2005.

SAMAIN, Etienne. As imagens não são bolas de sinuca. Como pensam as imagens. In: Como pensam as imagens. (org.) Etienne Samain. Campinas, SP: Ed. da UNICAMP, 2012.

SCHALLER, Jean-Jacques. Construir um viver junto na democracia renovada. In. Educação e Pesquisa. São Paulo. V. 28, n.2, p. 147-164, jul./Dez. 2002.

Lugares aprendentes e inteligência coletiva:rumo à constituição de um mundo comum. In: PASSEGGI, Maria da Conceição; SOUZAS, Elizeu Clementino de (Org.). (Auto) biografia: formação, territórios e saberes. Natal: UFRN/Paulus, 2008.

Les politiques de promotion de la santé et la question des lieux apprenants. In Revista

de Direito Sanitário, São Paulo. V.9, n 3 p. 36-74, 2008-2009. http://www.revistas.usp.br/rdisan/article/view/13129/14934 acessado <31/10/2015.

Traços de Linguagem, Cáceres, v. 3, n. 1 p. 109-124, 2019. 
SOUZA. Tânia Clemente. A análise do não verbal e os usos da imagem nos meios de comunicação. In: Revista RUA, NUDECRI, Campinas, SP. N.07, março, 2001.

VIOLA, Eduardo J. O Movimento Ecológico no Brasil ( 1974-1986): do ambientalismo à ecopolítica. In. Revista Brasileira de Ciências Sociais. N. ${ }^{\circ} 3$ e Vol. 1 fevereiro, 1987.

\section{Sites consultados:}

Revista Super Interessante In: https://super.abril.com.br/mundo-estranho/como-foi-criada-aorganizacao-das-nacoes-unidas/ acessado em novembro de 2018.

Vídeo - Organização das Nações Unidas - Disponível em: https://www.youtube.com/watch?v=cZNwiDrWOwU Acesso em julho/2018

https://www.cmvfxira.pt/uploads/writer_file/document/14320/Carta_das_Na_es_Unidas.pdacesso em novembro/2018.

https://nacoesunidas.org/carta/ acesso em outubro/2018.

https://pt.euronews.com/2018/06/08/cinco-novos-paises-no-conselho-de-seguranca-da-onu acesso novembro/2018.

Recebido em: janeiro de 2019. Aprovado em: abril de 2019.

Como citar este trabalho:

MOTTA, A. L. A. R. da. Sujeito, espaço e lixo, no dizer da mundialização. Traços de Linguagem. V.3, n.1, p. 109-124, 2019. 